\title{
MTLRP genetic polymorphism (214C $>$ A) was associated with Type 2 diabetes in Caucasian population: a meta-analysis
}

\author{
Li-Li Chen, Song-Mei Han, Fei-Fei Tang and Qiang Li
}

\begin{abstract}
Background: Previous studies reported the relation between MTLRP genetic polymorphism and type 2 diabetes, however, the conclusion were conflicting. In the present study, we performed a meta-analysis to reveal this association.

Methods: Literature retrieval, selection and assessment, data extraction, and meta-analyses were performed according to the RevMan 5.0 guidelines. In the meta-analysis, we utilized random-effect model or fixed-effect model to pool the Odds ratio (OR) according to the test of heterogeneity.

Results: A total of nine case-control studies included 4460 type 2 diabetes patients and 4114 healthy control subjects were analyzed. We did not found association between the MTLRP polymorphism and type 2 diabetes risk in the overall population (CC vs CA + AA: OR $=1.02 ; 95 \% \mathrm{Cl}: 0.89-1.17, \mathrm{P}=0.77 ; \mathrm{A}$ vs C: $\mathrm{OR}=1.02 ; 95 \% \mathrm{Cl}: 0.84-0.96$, $P=0.62)$. However, in subgroup analyses stratified by ethnicity, we found significant association of MTLRP polymorphism with type 2 diabetes in Caucasians (CC vs CA + AA: OR $=1.27$; $95 \%$ Cl: $1.02-1.57, \mathrm{P}=0.03$; A vs C: $\mathrm{OR}=0.74,95 \% \mathrm{Cl}: 0.60-0.91, \mathrm{P}=0.005)$.
\end{abstract}

Conclusion: The MTLRP polymorphism was associated with type 2 diabetes in Caucasians.

Keywords: MTLRP, Polymorphism, Type 2 diabetes, Meta-analysis

\section{Introduction}

The prevalence of type 2 diabetes is rapidly increasing and has become one of the most common chronic diseases worldwide [1,2]. Since type 2 diabetes is associated with an increased incidence of cardiovascular disease and longterm mortality, it imposes a significant economic burden on healthcare worldwide $[3,4]$. Recently, genetics were considered to be the main factor contributing to the development and progression of type 2 diabetes [5,6]. Therefore, the identification of genetic variants involved in individual susceptibility to type 2 diabetes can assist our understanding of the underlying disease process, and help to develop novel therapies.

Ghrelin is a 28 amino acid peptide with an n-octanoylated serine 3 residue primarily expressed in the X/A-like oxyntic cells of the stomach but also in the hypothalamus and

\footnotetext{
* Correspondence: qiang_li765@126.com

Department of Endocrinology, The Second Affiliated Hospital of Harbin Medical University, NO. 246, Xuefu Road, Nangang District, Harbin, Heilongjiang Province 150086, P.R. China
}

pancreas [7-10]. Ghrelin was discovered as the endogenous ligand of the growth hormone secretagogue receptor (GHSR). The peptide stimulates growth hormone release and appetite [11,12]. Administration of ghrelin in rodents induces weight gain by a reduction in fat utilization [13], and ghrelin stimulates appetite and regulates the weight balance through the GHSR by activation of neuropeptide Y (NPY) and agouti related peptide (AGRP) containing neurons in the hypothalamus $[14,15]$. MTLRP is a gene coding Ghrelin peptide and has been considered as a candidate gene for type 2 diabetes. The human MTLRP gene is located on chromosome 3 and consists of four exons and three introns. Several single nucleotide polymorphisms (SNPs) have been described within this gene. One missense polymorphism, $214 \mathrm{C}>\mathrm{A}$ at codon 72 with Met replacing Leu, is outside the region where the mature ghrelin product is encoded and its functional significance remains largely unknown. Recently, there were many genetic studies reported the association between this polymorphism and type 2 diabetes. However, evidence from 
these studies remains conflicting, rather than conclusive. Although the previous meta-analysis performed by Liao et al. in 2013 [16] has reported on the relation between this polymorphism and type 2 diabetes, it involved less literatures and had lower power. Furthermore, three important studies [17-19] were not included in Liao et al.'s studies. Therefore, for the present study, we have collected almost all published case-control studies to perform an update meta-analysis to further investigate the association between this SNP and risk for type 2 diabetes.

\section{Materials and methods}

\section{Literature collection and screening}

We searched and identified literatures in PubMed, EMBASE, ISI Web of Science, Wangfang in China and CNKI databases using the terms "MTLRP " or "ghrelin" or "preghrelin" and "polymorphism" or "SNP" or "Leu72Met" or "214C >A" and "type 2 diabetes".

\section{Inclusion and exclusion criteria}

The inclusion criteria was as follows: 1) the clinical research of direct comparison of MTLRP polymorphism between Type 2 diabetes and health control subjects without any restriction on language or publication year; 2) Type 2 diabetes patients were diagnosed according to WHO criteria or American Diabetes Association criteria without any restriction on age or racial; 3) the design was case-control study; and 4) genotypes were clearly reported or could be calculated.

\section{Literature quality assessment and data extraction}

Two independent reviewers (LLC and SMH) carried out the literature filtering and quality assessment. We excluded literatures obviously does not meet the inclusion criteria and duplicated publications. If inconsistencies existed, we resolved it through discussion. The Cochrane Handbook 5.0 Quality evaluation criteria were utilized to evaluate methodological quality of included studies. For each study, the following characteristics were extracted: the first author's last name, year of publication, country of origin, the numbers and age of cases and controls.

\section{Data analysis}

We utilized RevMan 5.0 software which was provided by the Cochrane Collaboration to perform the meta-analysis and to merge the OR values. We directly used Q-test and $\mathrm{I}^{2}$ test to examine the heterogeneity between each study. The OR value was utilized to evaluate the relationship between the MTLRP polymorphism and Type 2 diabetes. By heterogeneity test, if $\mathrm{P}>0.05$, we select the fixed effect mode1, and if $\mathrm{P}<0.05$, we select the random effect mode1 to merge OR. $\mathrm{P}<0.05$ was considered as significant difference. Analysis of sensitivity includes the difference of point estimation and confidence intervals of the combined effects value at a different model, to observe whether it changes the result. To test the publication bias, we utilized the RevMan 5.0 statistical software to make the funnel plot.

\section{Results}

\section{Literature screening}

As shown in Figure 1, there are 98 literatures preliminarily detected, and 89 literatures were excluded due to duplicated publication, not providing genotype data and non-clinical based research literature. A total of 9 literatures were included. These 9 studies [17-25] including 4460 patients with type 2 diabetes and 4114 healthy control subjects were included in this research.

\section{The characteristics of these studies}

As shown in Table 1, in these 9 studies, there were 3 studies carried out in Caucasian population, and 6 studies performed in Asian population. All these 9 studies provided genotype data and all are in line with Hardy-Weinberg equilibrium (HWE).

\section{The relation between MTLRP polymorphism and Type 2 diabetes}

There was not significant heterogeneity between each study $\left(\mathrm{P}=0.15, \mathrm{I}^{2}=33 \%\right)$ in overall population $(\mathrm{P}=0.15$, $\left.\mathrm{I}^{2}=33 \%\right)$ and in Caucasian population $\left(\mathrm{P}=0.44, \mathrm{I}^{2}=0 \%\right)$. Therefore, we utilized the fixed-effect model to merge OR value. The meta-analysis results (Figures 2 and 3 ) suggested that, in overall population, there are not significant differences between Type 2 diabetes and healthy control subjects in genotypes (CC vs CA + AA: $\mathrm{OR}=1.02 ; 95 \% \mathrm{CI}$ : $0.89-1.17, \mathrm{P}=0.77$ ) (Figure $2 \mathrm{~A}$ ) or alleles (A vs $\mathrm{C}$ : $\mathrm{OR}=1.02 ; 95 \%$ CI: $0.84-0.96, \quad \mathrm{P}=0.62$ ) distribution (Figure 3A). However, in Caucasian population, subjects with $\mathrm{A}$ allele have decreased risk for Type 2 diabetes $(\mathrm{OR}=0.74,95 \% \mathrm{CI}: 0.60-0.91, \mathrm{P}=0.005$ ) (Figures $2 \mathrm{~B}$ and $3 \mathrm{~B})$.

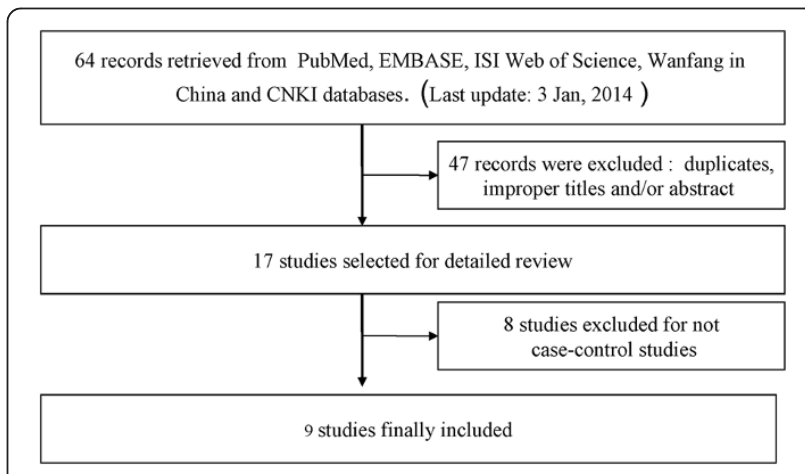

Figure 1 Flow chart of selection of literatures. 
Table 1 The characteristics of included studies

\begin{tabular}{|c|c|c|c|c|c|c|c|}
\hline \multirow[t]{2}{*}{ Authors } & \multirow[t]{2}{*}{ Publication year } & \multirow[t]{2}{*}{ Country } & \multirow[t]{2}{*}{ Ethnicity } & \multirow[t]{2}{*}{ Case/control (n) } & \multicolumn{2}{|l|}{ Age } & \multirow[t]{2}{*}{ HWE } \\
\hline & & & & & Case & Control & \\
\hline Larsen et al. [24] & 2005 & Denmark & Caucasian & $557 / 233$ & $60 \pm 11$ & $52 \pm 14$ & Yes \\
\hline Kim et al. [23] & 2006 & Korea & Asian & $206 / 80$ & $56.4 \pm 10.1$ & $54.9 \pm 9.5$ & Yes \\
\hline Choi et al. [22] & 2006 & Korea & Asian & $760 / 641$ & $59 \pm 10$ & $65 \pm 4$ & Yes \\
\hline Berthold et al. [20] & 2009 & Germany & Caucasian & $420 / 430$ & $61 \pm 12$ & $63 \pm 7$ & Yes \\
\hline Garcia et al. [25] & 2009 & France & Caucasian & $610 / 820$ & 60 & 52 & Yes \\
\hline Liu J, et al. [18] & $2012 a$ & China & Asian & $864 / 877$ & $53 \pm 11$ & $53 \pm 12$ & Yes \\
\hline Liu J, et al. [21] & $2012 b$ & China & Asian & $744 / 1024$ & $56 \pm 8$ & $54 \pm 11$ & Yes \\
\hline Xu et al. [19] & 2008 & China & Asian & $333 / 202$ & $50 \pm 8$ & $49 \pm 6$ & Yes \\
\hline Zhang et al. [17] & 2011 & China & Asian & $138 / 113$ & $54 \pm 12$ & $54 \pm 15$ & Yes \\
\hline
\end{tabular}

\section{Sensitivity analysis}

We deleted one single study from the overall pooled analysis each time to check the influence of the removed data set to the overall ORs. The pooled ORs and 95\% CIs were not significantly altered when any part of the study was omitted, which indicated that any single study had little impact on the overall ORs.

\section{Publication bias analysis}

We analyzed publication bias by use of Revman 5.2 software, the funnel plot (Figure 4) shows the points evenly distributed, symmetrical, and most of the points are within the $95 \%$ confidence interval. It indicates there is no publication bias, and the result of study is credible.

\section{Discussion}

In the present study, we found an association of MTLRP genetic polymorphism (214C>A) with Type 2 diabetes in Caucasian population. However, we did not found this association in Asian population.

Several previous studies suggested that MTLRP 214C>A polymorphism was associated with the risk for type 2 diabetes. However, other case-control studies reported conflicting results. This may partly be due to a small sample size in each of the published studies and ethnic difference. Meta-analysis is a useful statistical method that combines findings from independent studies. In the present study, we found that, in Caucasians, the risk for type 2 diabetes was decreased in subjects with $\mathrm{C}$ allele or $\mathrm{CC}$ genotype. 


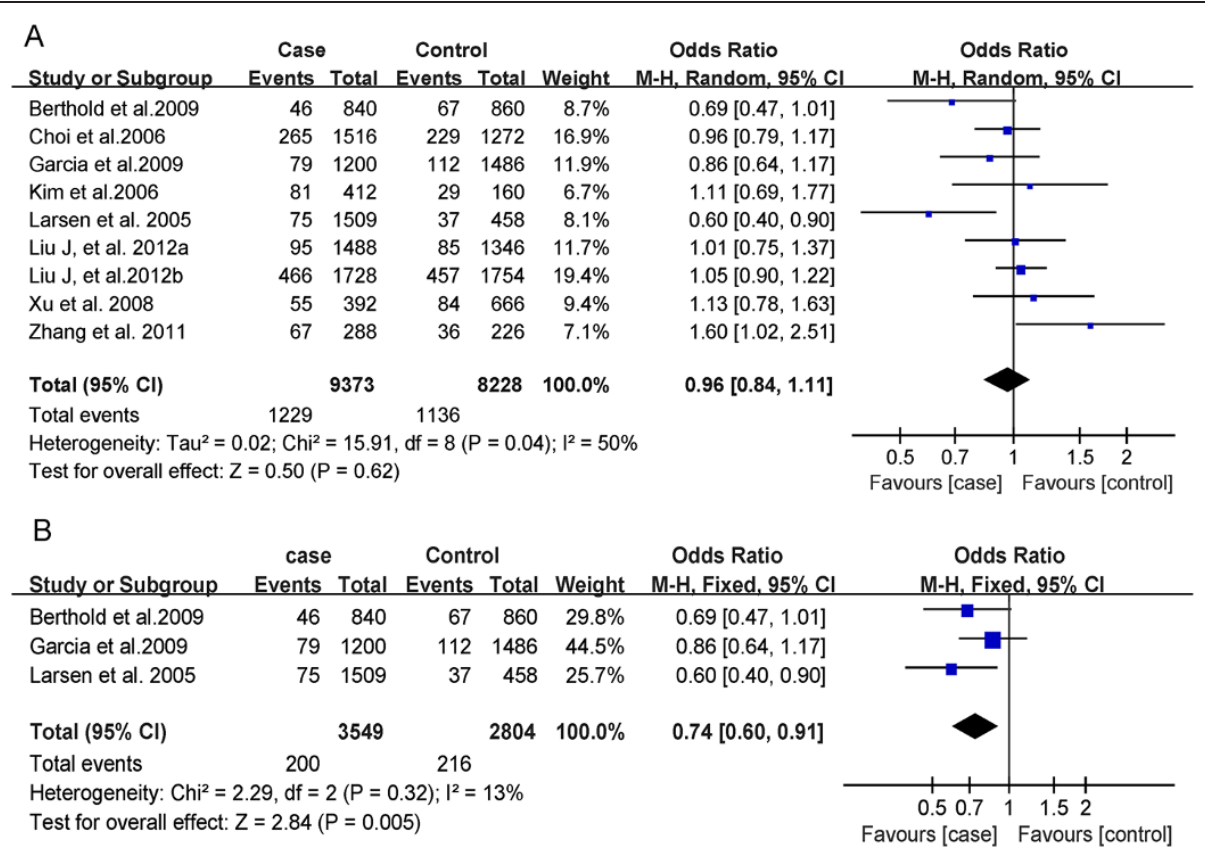

Figure 3 Forest plot of MTLRP genetic polymorphism (214C>A) and Type 2 diabetes (A allele vs C allele), the horizontal lines correspond to the study-specific OR and $95 \% \mathrm{Cl}$, respectively. The area of the squares reflects the study-specific weight. The diamond represents the pooled results of OR and $95 \% \mathrm{Cl}$. (A: In total; B: In Caucasian).

However, this association was not found in Asians. The reason for this discrepancy may be as follows: 1) there are different genetic backgrounds between Caucasians and Asian, which plays an important role; and 2) type 2 diabetes is a sophisticated disease which is affected by an interaction between many factors, including environmental exposure, life style, socioeconomic status and individual susceptibility. It is possible that individual susceptibility in different ethnic group may be modified by environmental exposure, life style and socioeconomic status in a different way.

Further more, although we have found a positive association of MTLRP polymorphism with Type 2 diabetes in

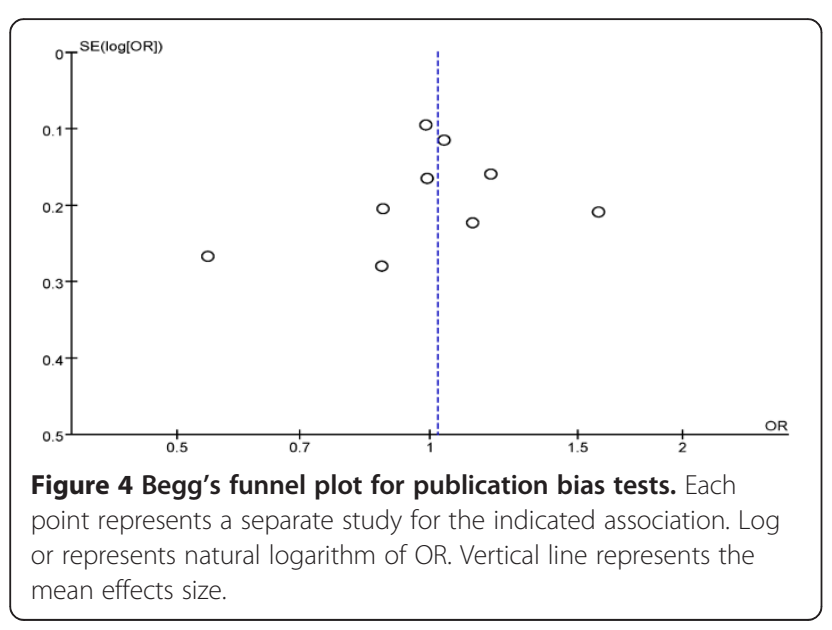

Caucasian population, the total sample size of Caucasians in this meta-analysis is still relatively small, which may restrict the statistical power for achieving a definitive conclusion. Therefore, case-control studies in larger samples are needed to confirm this correlation found in Caucasians.

In addition, the characteristic of meta-analysis is to combine comparable studies to increase the sample size and statistical power and draw a more compelling result. However, meta-analysis confounds factors such as publication bias, method of sampling, different genetic backgrounds of subjects, different protocols and quality of analysis. In the present study, we did not found the publication bias, and the genotypes in all studies were detected with genetic DNA from blood samples using PCR-RFLP genotyping methods. All of the studies checked genotypes for quality control. Genotype distribution of controls in all studies was consistent with HWE.

Exploring heterogeneity is one of the important goals of meta-analysis. In the present study no significant heterogeneity was found among the included studies. Sensitivity analysis also showed that omission of any single study did not have significant impact on the combined ORs. This made the results of this meta-study more reliable to some extent.

However, there remained some limitations in this metaanalysis. Although the genotyping methods used in all the studies were the same, other clinical factors such as age, sex and different treatment in each study might lead to 
bias. Determining whether or not these factors influence the results of this meta-analysis would need further investigation. In addition, although we concluded that there is no bias in our study by statistical analysis, in reality we all know that the papers having negative results were probably published with more difficultly. Therefore, the inevitable publication bias may exist in the results.

\section{Conclusion}

Our study suggested that $214 \mathrm{C}>\mathrm{A}$ polymorphism in the MTLRP gene was associated with risk of Type 2 diabetes in Caucasian population. Larger well-designed epidemiological studies with ethnically diverse populations and functional evaluations are warranted to confirm our findings.

\section{Competing interests}

The authors declare that they have no competing interests.

\section{Authors' contributions}

LLC and SMH conceived the study, participated in the design, collected the data, performed statistical analyses, and drafted the manuscript. FFT and QL conceived the study, participated in the design, and helped to draft the manuscript. All authors read and approved the final manuscript.

\section{Acknowledgements}

The present study was supported by Heilongjiang Provincial Department of Education Research Fund (11531128)

Received: 4 April 2014 Accepted: 18 June 2014

Published: 5 August 2014

\section{References}

1. Shaw JE, Sicree RA, Zimmet PZ: Global estimates of the prevalence of diabetes for 2010 and 2030. Diabetes Res Clin Pract 2010, 87:4-14.

2. American Diabetes Association: Economic costs of diabetes in the U.S. in 2012. Diabetes Care 2013, 36:1033-1046.

3. Zhang P, Zhang X, Brown J, Vistisen D, Sicree R, Shaw J, Nichols G: Global healthcare expenditure on diabetes for 2010 and 2030. Diabetes Res Clin Pract 2010, 87:293-301

4. Dailey G: Early and intensive therapy for management of hyperglycemia and cardiovascular risk factors in patients with type 2 diabetes. Clin Ther 2011, 33:665-678.

5. Tekola-Ayele F, Adeyemo AA, Rotimi CN: Genetic epidemiology of type 2 diabetes and cardiovascular diseases in Africa. Prog Cardiovasc Dis 2013, 56:251-260

6. Abbas S, Raza ST, Ahmed F, Ahmad A, Rizvi S, Mahdi F: Association of genetic polymorphism of PPARY-2, ACE, MTHFR, FABP-2 and FTO genes in risk prediction of type 2 diabetes mellitus. J Biomed Sci 2013, 20:80.

7. Nakazato M, Murakami N, Date Y, Kojima M, Matsuo H, Kangawa K, Matsukura S: A role for ghrelin in the central regulation of feeding. Nature 2001, 409:194-198.

8. Kojima M, Hosoda H, Matsuo H, Kangawa K: Ghrelin: discovery of the natural endogenous ligand for the growth hormone secretagogue receptor. Trends Endocrinol Metab 2001, 12:118-122.

9. Date Y, Nakazato M, Hashiguchi S, Dezaki K, Mondal MS, Hosoda H, Kojima M, Kangawa K, Arima T, Matsuo H, Yada T, Matsukura S: Ghrelin is present in pancreatic alpha-cells of humans and rats and stimulates insulin secretion. Diabetes 2002, 51:124-129.

10. Gnanapavan S, Kola B, Bustin SA, Morris DG, McGee P, Fairclough P, Bhattacharya S, Carpenter R, Grossman AB, Korbonits M: The tissue distribution of the mRNA of ghrelin and subtypes of its receptor, GHS-R, in humans. J Clin Endocrinol Metab 2002, 87:2988-2991.

11. Takaya K, Ariyasu H, Kanamoto N, Iwakura H, Yoshimoto A, Harada M, Mori K, Komatsu Y, Usui T, Shimatsu A, Ogawa Y, Hosoda K, Akamizu T, Kojima M, Kangawa K, Nakao K: Ghrelin strongly stimulates growth hormone release in humans. J Clin Endocrinol Metab 2000, 85:4908-4911.
12. Lawrence CB, Snape AC, Baudoin FM, Luckman SM: Acute central ghrelin and $\mathrm{GH}$ secretagogues induce feeding and activate brain appetite centers. Endocrinology 2002, 143:155-162.

13. Tschfp M, Smiley DL, Heiman ML: Ghrelin induces adiposity in rodents. Nature 2000, 407:908-913.

14. Kamegai J, Tamura H, Shimizu T, Ishii S, Sugihara H, Wakabayashi I: Chronic central infusion of ghrelin increases hypothalamic neuropeptide $Y$ and Agouti-related protein mRNA levels and body weight in rats. Diabetes 2001, 50:2438-2443.

15. Chen HY, Trumbauer ME, Chen AS, Weingarth DT, Adams JR, Frazier EG, Shen Z, Marsh DJ, Feighner SD, Guan XM, Ye Z, Nargund RP, Smith RG Van der Ploeg LH, Howard AD, MacNeil DJ, Qian S: Orexigenic action of peripheral ghrelin is mediated by neuropeptide $Y$ and agouti-related protein. Endocrinology 2004, 145:2607-2612

16. Liao N, Xie ZK, Huang J, Xie ZF: Association between the ghrelin Leu72Met polymorphism and type 2 diabetes risk: a meta-analysis. Gene 2013, 517:179-183.

17. Zhang SL, Liu J, Guo Q, Liu X: Relationship between Ghrelin gene Ar951GIn and Leu72Met polymorphism and Type 2 diabetes and blood lipids levels in Hui population. Lanzhou Univ J Med Ed 2011, 37:21-24.

18. Liu J, Liu J, Zhang SL, Zhang YL, Liu JX, Guo Q, Bing YJ, Wang YF: Association of ghrelin gene polymorphism with type 2 diabetes and lipid metabolism in Dongxiang, Hui and Han population. Chi J Diabetes 2012, 4:290-295.

19. $\mathrm{Xu} \mathrm{LL}$, Xiang HD: Correlation between Ghrelin gene polymorphism and type 2 diabetes. Preclinic Clin 2008, 28:44-47.

20. Berthold HK, Giannakidou E, Krone W, Mantzoros CS, Gouni-Berthold I: The Leu72Met polymorphism of the ghrelin gene is associated with a decreased risk for type 2 diabetes. Clin Chim Acta 2009, 399:112-116.

21. Liu J, Liu J, Tian LM, Liu JX, Bing YJ, Zhang JP, Wang YF, Zhang LY: Association of ghrelin Leu72Met polymorphism with type 2 diabetes mellitus in Chinese population. Gene 2012, 504:309-312.

22. Choi HJ, Cho YM, Moon MK, Choi HH, Shin HD, Jang HC, Kim SY, Lee HK, Park KS: Polymorphisms in the ghrelin gene are associated with serum high-density lipoprotein cholesterol level and not with type 2 diabetes mellitus in Koreans. J Clin Endocrinol Metab 2006, 91:4657-4663.

23. Kim SY, Jo DS, Hwang PH, Park JH, Park SK, Yi HK, Lee DY: Preproghrelin Leu72Met polymorphism is not associated with type 2 diabetes mellitus. Metabolism 2006, 55:366-370.

24. Larsen LH, Gjesing AP, Sørensen TI, Hamid YH, Echwald SM, Toubro S, Black E, Astrup A, Hansen T, Pedersen O: Mutation analysis of the preproghrelin gene: no association with obesity and type 2 diabetes. Clin Biochem 2005, 38:420-424

25. Garcia EA, King P, Sidhu K, Ohgusu H, Walley A, Lecoeur C, Gueorguiev M, Khalaf S, Davies D, Grossman AB, Kojima M, Petersenn S, Froguel P, Korbonits $\mathrm{M}$ : The role of ghrelin and ghrelin-receptor gene variants and promoter activity in type 2 diabetes. Eur J Endocrinol 2009, 161:307-315.

doi:10.1186/1476-511X-13-124

Cite this article as: Chen et al:: MTLRP genetic polymorphism (214C $>$ A) was associated with Type 2 diabetes in Caucasian population: a meta-analysis. Lipids in Health and Disease 2014 13:124

\section{Submit your next manuscript to BioMed Central and take full advantage of:}

- Convenient online submission

- Thorough peer review

- No space constraints or color figure charges

- Immediate publication on acceptance

- Inclusion in PubMed, CAS, Scopus and Google Scholar

- Research which is freely available for redistribution 